\title{
Е.П. ГЕРАСИМОВ,
}

Новосибирский государственный университет

архитектуры, дизайна и искусств

\section{К ВОПРОСУ НОРМИРОВАНИЯ НАДЕЖНОСТИ ПО ДЕФОРМАЦИЯМ ЖЕЛЕЗОБЕТОННЫХ ИЗГИБАЕМЫХ КОНСТРУКЦИЙ}

К любой строительной конструкции предъявляют определенные требования по прочности, жесткости, трещиностойкости и т. д. Данные требования подтверждаются соответствующими расчетами. Выполнение всех требований обеспечивает конструкции необходимую надежность. Но в связи с тем, что в настоящее время расчеты строительных конструкций выполняются по методу предельных состояний, численное значение надежности по данному методу определить невозможно. Это можно сделать, только применив вероятностные методы расчета. Одним из серьезных препятствий применению вероятностных методов является отсутствие нормированных значений надежности (нормативной надежности) строительных конструкций.

Большое развитие вероятностные методы расчетов получили во второй половине $\mathrm{XX}$ в., но назначение нормативных значений надежности наталкивалось на определенные препятствия. Наиболее серьезным препятствием является учет последствий отказа, т. к. некоторые последствия не поддаются какой-либо количественной оценке. С другой стороны, подавляющий объем работ связан с назначением нормативной надежности строительных конструкций исходя из их несущей способности. Работ, связанных с нормированием надежности по деформациям, трещиностойкости, очень мало.

Настоящая статья посвящена вопросу определения нормативной надежности по деформациям железобетонных изгибаемых конструкций исходя только из физиологических требований. Предложен и описан метод определения нормативной надежности, основанный на чувствительности человека к колебаниям. Представлен пример определения нормативной надежности по деформациям сборных железобетонных плит перекрытия на основе предложенного метода.

Ключевые слова: железобетонные изгибаемые конструкции; нормативная надежность; вероятностные методы расчета; деформация; сборные железобетонные плиты перекрытия.

Для цитирования: Герасимов Е.П. К вопросу нормирования надежности по деформациям железобетонных изгибаемых конструкций // Вестник Томского государственного архитектурно-строительного университета. 2019. Т. 21. № 5. C. $115-126$.

DOI: $10.31675 / 1607-1859-2019-21-5-115-126$

E.P. GERASIMOV

Novosibirsk State University of Architecture, Design and Fine Arts

\section{DETERMINATION OF REGULATORY RELIABILITY FOR DEFORMATION OF REINFORCED-CONCRETE FLEXIBLE STRUCTURES}

Strength, stiffness, crack resistance requirements must be specified for any structure. These requirements are provided by the appropriate calculations. Compliance with all requirements 
ensures the design reliability. But due to the fact that structural analysis is performed by the limit state method, the numerical value of the reliability cannot be determined. This can be done only by applying probabilistic methods of calculation. One of the major obstacles to the use of probabilistic methods is the lack of standardized values of the structural reliability (normative reliability).

Although probabilistic methods of calculation were developed in late in the 20th century, the assignment of normative reliability values encountered serious obstacles. The most serious obstacle was the consideration of the failure consequences as some consequences were quantifiable. On the other hand, much work concerned the assignment of normative structural reliability based on their bearing capacity. Only few works related to the reliability normalization using deformation and crack resistance.

This paper deals with the regulatory definition of reliability using the deformation of reinforced-concrete bendings based on physiological requirements. A method for determining the normative reliability based on human sensitivity to fluctuations is proposed. The normative reliability of precast slabs is determined using the proposed method.

Keywords: reinforced-concrete flexible structures; normative reliability; probabilistic calculation methods; deformation; precast slabs.

For citation: Gerasimov E.P. K voprosu normirovaniya nadezhnosti po deformatsiyam zhelezobetonnykh izgibaemykh konstruktsii [Determination of regulatory reliability for deformation of reinforced-concrete flexible structures]. Vestnik Tomskogo gosudarstvennogo arkhitekturno-stroitel'nogo universiteta - Journal of Construction and Architecture. 2019. V. 21. No. 5. Pp. 115-126.

DOI: $10.31675 / 1607-1859-2019-21-5-115-126$

Проектирование любой строительной конструкции подразумевает проведение ряда расчетов по прочности, устойчивости, жесткости и другим параметрам в зависимости от вида конструкции. Расчет по деформациям входит во вторую группу предельных состояний и включает в себя расчет по определению вертикальных перемещений конструкций (прогибов).

Расчет по деформациям сводится к выполнению неравенства

$$
f \leq[f],
$$

где $f$ - прогиб от действующих нагрузок; [f] - предельный прогиб.

СП 20.13330.2016 «Нагрузки и воздействия» установил предельные значения прогибов исходя из ряда требований:

- технологических;

- физиологических;

- конструктивных;

- эстетико-психологических.

Если выполняется расчет по вероятностному методу, то неравенство (1) преобразится и примет вид

$$
P_{f} \geq\left\lfloor P_{f}\right\rfloor
$$

где $P_{f}$ - вероятность того, что фактический прогиб не превышает предельнодопустимое значение (вероятность безотказной работы по деформации или надежность по деформации); $\left[P_{f}\right]$ - минимально допустимое значение вероятности того, что прогиб не превысит предельно допустимого значения (нормативная надежность по деформациям).

Определение вероятности безотказной работы по деформации не представляет собой очень сложную задачу. При определении значения норматив- 
ной надежности встречаются определенные трудности. Данные трудности выражаются в учете последствий отказов. Эти последствия подразделяются на экономически исчисляемые и экономически неисчисляемые (социальные). Каждое требование, предъявляемое к предельным прогибам, может быть отнесено к тому или иному последствию (рис. 1).

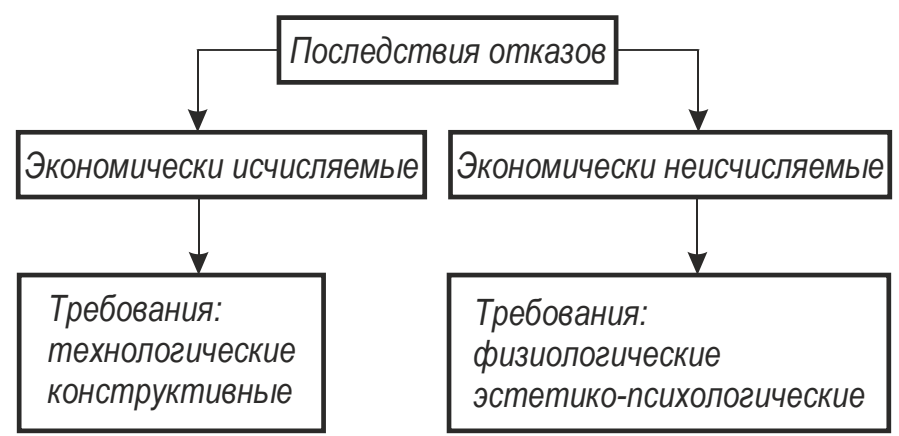

Puc. 1. Классификация требований в зависимости от последствий отказов

Значительно больший интерес представляет метод определения значения нормативной надежности с учетом экономически неисчисляемых последствий отказа. Это связано с тем, что расчет по деформациям выполняется для изгибаемых элементов, а подавляющее большинство изгибаемых конструкций в промышленном и гражданском строительстве - это железобетонные плиты перекрытия и покрытия. Предельные деформации таких конструкций установлены исходя из физиологических и (или) эстетико-психологических требований.

Существует ряд предложений по назначению нормативной надежности в пределах 0,9-0,999 [1-5]. Но данные значения установлены исходя из пригодности к нормальным условиям эксплуатации в целом и не дифференцированы в зависимости от вида расчета и последствий отказа. В связи с этим очень актуален вопрос разработки методики определения нормативной надежности по деформациям в зависимости от последствий отказа.

Рассмотрим метод определения нормативной надежности по деформациям с учетом только физиологических требований. Потери, возникающие в случае наступления отказа, не поддаются количественной оценке. Для учета потерь предлагается заменить потери некими «рабочими характеристиками», с помощью которых может быть решена поставленная задача. Одной из таких характеристик может служить параметр вибрации, воздействующей на человеческий организм [6-8].

Человек весьма чувствителен к колебаниям, и эта чувствительность изменяется в довольно широких пределах. Характер восприятия может быть определен шестью категориями чувствительности [9]. Каждая категория характеризуется предельными амплитудами ускорения (табл. 1).

Амплитуда ускорения выражается формулой [9]

$$
W(\alpha)=\frac{b_{r} \cdot X_{r}(\alpha)}{p_{r}^{2}-\omega^{2}} \omega^{2},
$$


где $b_{r}$ - коэффициент разложения нагрузки; $X_{r}(\alpha)$ - нормированная форма собственных колебаний; $p_{r}$ - круговая частота; $\omega$ - частота колебаний.

Характеристика воздействия колебаний на людей в зависимости

Таблица 1 от ускорения гармонических перемещений

\begin{tabular}{|l|c|}
\hline \multicolumn{1}{|c|}{$\begin{array}{c}\text { Характеристика воздействия } \\
\text { колебаний на людей }\end{array}$} & $\begin{array}{c}\text { Предельные амплитуды ускорения, } \\
\text { мм/ } \text { c }^{2} \text { (для частот до 10 Гц) }\end{array}$ \\
\hline Неощутимые & 10 \\
\hline Слабо ощутимые & 40 \\
\hline Хорошо ощутимые & 125 \\
\hline Сильно ощутимые & 400 \\
\hline Вредны при длительном воздействии & 1000 \\
\hline Безусловно вредны & Более 1000 \\
\hline
\end{tabular}

Индекс $r$ обозначает номер частоты, соответствующей номеру тона собственных колебаний, $\alpha$ - относительная абсцисса.

Значение круговой частоты зависит от изгибной жесткости, способа опирания конструкции и вида действующих нагрузок [9]. Таким образом, амплитуда ускорения зависит от изгибной жесткости конструкции. А значит, между амплитудой ускорения и деформацией конструкции существует определенная связь.

В качестве базовой модели при определении нормативной надежности предлагается использовать вероятностно-оптимизационную модель [10]:

$$
C=C_{0}+C_{f} \cdot Q_{f} \rightarrow \min .
$$

Вместо экономических показателей $\left(C_{0}\right.$ и $\left.C_{f}\right)$ предлагается применить некие величины, характеризующие чувствительность человека к амплитуде ускорения:

- $C_{0}$ - мера чувствительности человека к амплитуде ускорения при определенной изгибной жесткости конструкции;

- $C_{f}$ - предельная мера чувствительности человека.

Для удобства расчетов формулу (2) представим в следующем виде:

$$
C=\left(1-\frac{C_{0}}{C_{f}}\right)+C_{f} \cdot Q_{f} \rightarrow \min .
$$

Соотношение $C_{0} / C_{f}$ есть некая величина чувствительности человека. Она колеблется от 0 до 1 . Если это соотношение близко к 0 , то увеличиваются благоприятные условия, при этом вероятность отказа $Q_{f}$ уменьшается. При увеличении к 1, наоборот, все сильнее будет ощущаться дискомфорт, и вероятность отказа увеличится.

$C_{0}$ и $C_{f}$ предлагается определять при помощи графика, приведенного на рис. 2. 


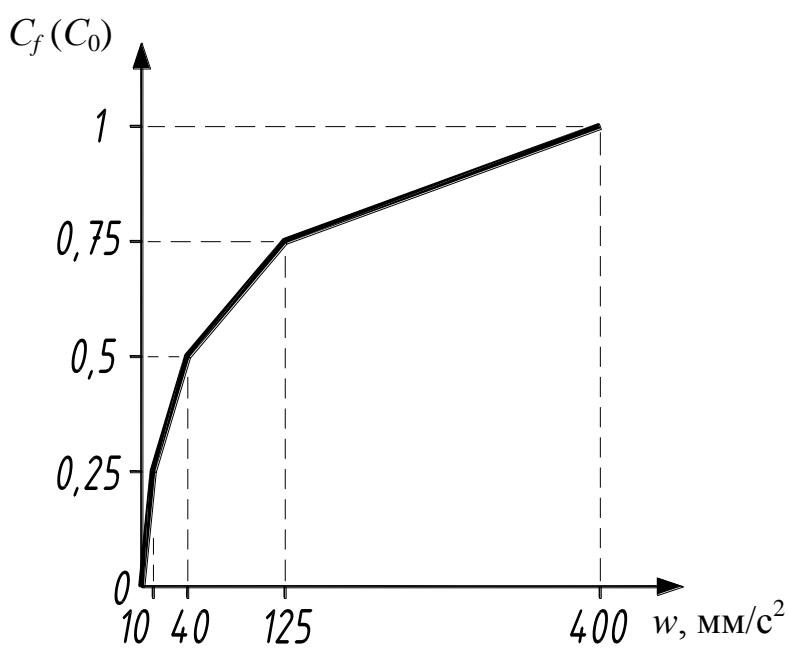

Puc. 2. Зависимость меры чувствительности человека от амплитуды ускорения

По оси абсцисс указаны значения амплитуд ускорений, по оси ординат мера чувствительности человека. Ордината разделена поровну на четыре участка:

- от 0 до 0,25 - колебания неощутимы для человека;

- от 0,25 до 0,5 - колебания слабо ощущаются;

- от 0,5 до 0,75 - колебания хорошо ощущаются;

- от 0,75 до 1 - колебания ощущаются сильно.

Каждому значению ординаты соответствует определенная величина амплитуды ускорения согласно табл. 1. При построении графика предельное значение амплитуды ускорения принято равным 400 мм/ $\mathrm{c}^{2}$, которой соответствует максимальная, самая неблагоприятная, мера чувствительности человека - 1 .

Предельная мера амплитуды ускорения в 400 мм/ $\mathrm{c}^{2}$ принята из соображения, что для большинства строительных конструкций вряд ли можно ожидать амплитуду ускорений более $400 \mathrm{~mm} / \mathrm{c}^{2}$.

Порядок определения нормативной надежности следующий:

1. Исходя из предельного прогиба $[f]$ определяется минимально допустимая изгибная жесткость конструкции при известных действующих нагрузках.

2. По формуле (1) определяется амплитуда ускорения при минимально допустимой изгибной жесткости. Данное значение амплитуды будет являться предельно допустимым для рассматриваемой конструкции.

3. Исходя из предельно допустимой амплитуды по графику на рис. 2 определяется предельная мера чувствительности человека $-C_{f}$.

4. Производится варьирование изгибной жесткости конструкции с определенным шагом.

При каждом значении изгибной жесткости определяется:

- амплитуда ускорения по формуле (3);

- мера чувствительности человека $\left(C_{0}\right)$ по графику на рис. 2 в зависимости от значения вычисленной амплитуды ускорения; 
- среднее значение $\bar{f}$ и среднеквадратическое отклонение прогиба конструкции $-S_{f}$;

- вероятность отказа $\left(Q_{f}\right)$, как вероятность достижения предельно допускаемого прогиба

$$
\beta=\frac{[f]-\bar{f}}{S_{f}}, Q_{f}=0,5-\Phi(\beta) ;
$$

- величина $C$ по формуле (5).

Таким образом, варьируя жесткостью конструкции, можно добиться такого состояния, при котором в формуле (5) $C=\min$. По вероятности отказа $Q_{f}$ при $C=\min$ определяется нормативная надежность:

$$
\left[P_{f}\right]=1-Q_{f}
$$

По предлагаемой методике была определена нормативная надежность по деформациям сборных железобетонных многопустотных плит перекрытия, изготовляемых по серии 1.141-1.

Расчет выполнен согласно предложенному выше порядку.

Предельный прогиб определялся согласно подразделу Е.2.2 СП 20.13330.2016 «Нагрузки и воздействия». Минимальная изгибная жесткость определялась по формуле

$$
D_{\min }=\frac{s \cdot q \cdot \ell^{4}}{8 \cdot[f]},
$$

где $s$ - коэффициент, зависящий от расчетной схемы; $q$ - значение нормативной нагрузки, действующей на конструкцию; $\ell$ - пролет конструкции; $[f]$ - предельный допускаемый прогиб.

В качестве нормативной нагрузки принималась максимальная нагрузка, указанная в серии на плиты.

При известной минимальной изгибной жесткости определялись максимальные амплитуды ускорения по формуле (3) и предельная мера чувствительности человека - по графику на рис. 2 .

Производилось варьирование жесткости конструкции, и при каждом значении жесткости были определены амплитуда ускорения, мера чувствительности человека, среднее значение и среднее квадратическое отклонение прогиба, вероятность отказа.

При вычислении амплитуды ускорения коэффициент разложения нагрузки и нормированная форма собственных колебаний определялись в зависимости от расчетной схемы.

Коэффициент разложения нагрузки определялся по формуле [9]

$$
b_{r}=\frac{2 \sqrt{2} \cdot v \cdot c \cdot \omega^{2}}{\pi \cdot q},
$$

где $v$ - нагрузка, создающая колебания. В расчет принято $v=50$ кг $/ \mathrm{M}^{2} ; c-$ величина амплитуды вертикальных колебаний. Значение величины принято 2,5 см [6]; $\omega=2 \cdot \pi \cdot n$ - частота колебаний. Частота ходьбы $-n$, принята 
равной 1,5 Гц [6]; $q$ - величина полной нагрузки, действующей на конструкцию. Величина нагрузки принята согласно серии. муле [9]

Нормированная форма собственных колебаний определялась по фор-

$$
X_{r}(\alpha)=\sqrt{2} \sin (\pi \cdot \alpha) .
$$

Круговая частота определялась по формуле [9]

$$
p_{r}=\frac{\lambda_{r}^{2}}{\ell^{2}} \sqrt{\frac{D}{\mu}},
$$

где $\lambda_{r}^{2}$ - квадрат коэффициента $r$-й частоты. В расчет принято $r=1, \lambda_{1}^{2}=9,87$;

$\ell$ - пролет конструкции; $D$ - изгибная жесткость конструкции; $\mu=\frac{q}{g}-$ приведенная равномерно распределенная масса $\left(g=9,81 \mathrm{м} / \mathrm{c}^{2}\right)$.

Среднее значение прогиба определялось при средних показателях модулей упругости бетона, арматуры и геометрических размерах поперечного сечения конструкции по методике СП 63.13330.2012 «Бетонные и железобетонные конструкции».

Средние показатели модулей упругости бетона и арматуры принимались по справочным данным [12] в зависимости от марки бетона и класса арматуры, указанных в серии. Средние значения геометрических размеров, а также постоянные и временные нагрузки принимались также на основе данных серии. Согласно серии марка бетона - M200, класс арматуры - АтVт.

Средние квадратические отклонения показателей вычислялись по формуле [13]

$$
s=\frac{\Delta}{6 \cdot M},
$$

где $s$ - среднее квадратическое отклонение показателя; $\Delta$ - величина допуска показателя; $M$ - среднее значение показателя.

Варьирование жесткости производилось путем изменения площади сечения продольной арматуры.

При расчетах применялся метод статистического моделирования [11].

Нормативная надежность была определена для 19 плит различной ширины, пролета и нагрузки. Результаты расчета приведены в табл. 2.

Таблица 2

Результаты расчета

\begin{tabular}{|c|l|c|}
\hline № плиты & \multicolumn{1}{|c|}{ Марка плиты } & Величина нормативной надежности \\
\hline 1 & ПК 51.10-8АтVт & 0,983368 \\
\hline 2 & ПК 54.10-8АтVт & 0,982118 \\
\hline 3 & ПК 57.10-8АтVт & 0,981144 \\
\hline 4 & ПК 60.10-8АтVт & 0,980183 \\
\hline 5 & ПК 54.15-8АтVт & 0,979723 \\
\hline
\end{tabular}


Окончание табл. 2

\begin{tabular}{|c|l|c|}
\hline № плиты & \multicolumn{1}{|c|}{ Марка плиты } & Величина нормативной надежности \\
\hline 6 & ПК 57.15-8АтVт & 0,977421 \\
\hline 7 & ПК 60.15-8АтVт & 0,976474 \\
\hline 8 & ПК 63.15-8АтVт & 0,975071 \\
\hline 9 & ПК 51.10-6АтVт & 0,985184 \\
\hline 10 & ПК 54.10-6АтVт & 0,984160 \\
\hline 11 & ПК 57.10-6АтVт & 0,983168 \\
\hline 12 & ПК 60.10-6АтVт & 0,981594 \\
\hline 13 & ПК 54.12-6АтVт & 0,983863 \\
\hline 14 & ПК 57.12-6АтVт & 0,982331 \\
\hline 15 & ПК 60.12-6АтVт & 0,980900 \\
\hline 16 & ПК 63.12-6АтVт & 0,979371 \\
\hline 17 & ПК 57.15-6АтVт & 0,979664 \\
\hline 18 & ПК 60.15-6АтVт & 0,979783 \\
\hline 19 & ПК 63.15-6АтVт & 0,976277 \\
\hline
\end{tabular}

Результаты позволяют сделать следующие выводы:

1. Ни одно из значений нормативной надежности не составляет меньше 0,95 .

2. Значения нормативной надежности зависят от пролета, ширины плиты, а также действующей нагрузки:

- с увеличением пролета и ширины плит нормативная надежность уменьшается. Зависимость при этом близка к линейной (рис. 3-8);

- с увеличением нагрузки на плиту нормативная надежность увеличивается.

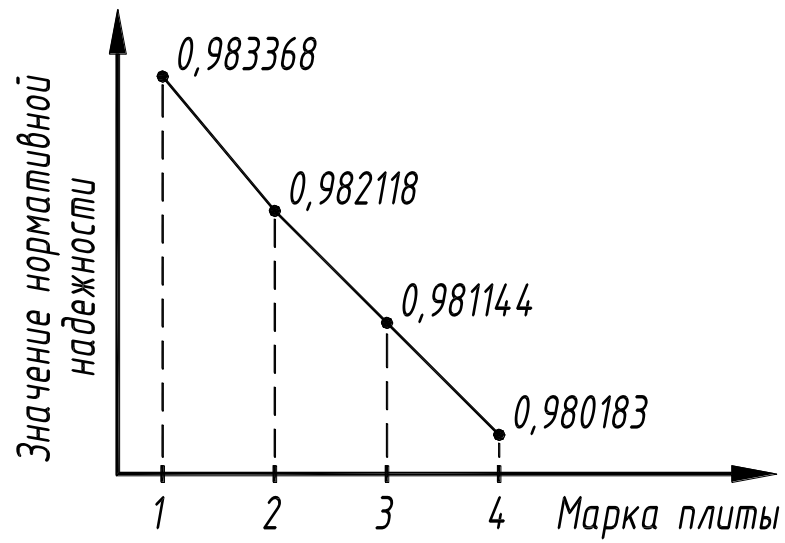

Puc. 3. Зависимость нормативной надежности от пролета плит (номинальная ширина $1 \mathrm{M}$, нагрузка $\left.-800 \mathrm{\kappa г} / \mathrm{M}^{2}\right)$ :

1 - плита ПК 51.10-8АтVт; 2 - плита ПК 54.10-8АтVт; 3 - плита ПК 57.108АтVт; 4 - плита ПК 60.10-8АтVт 


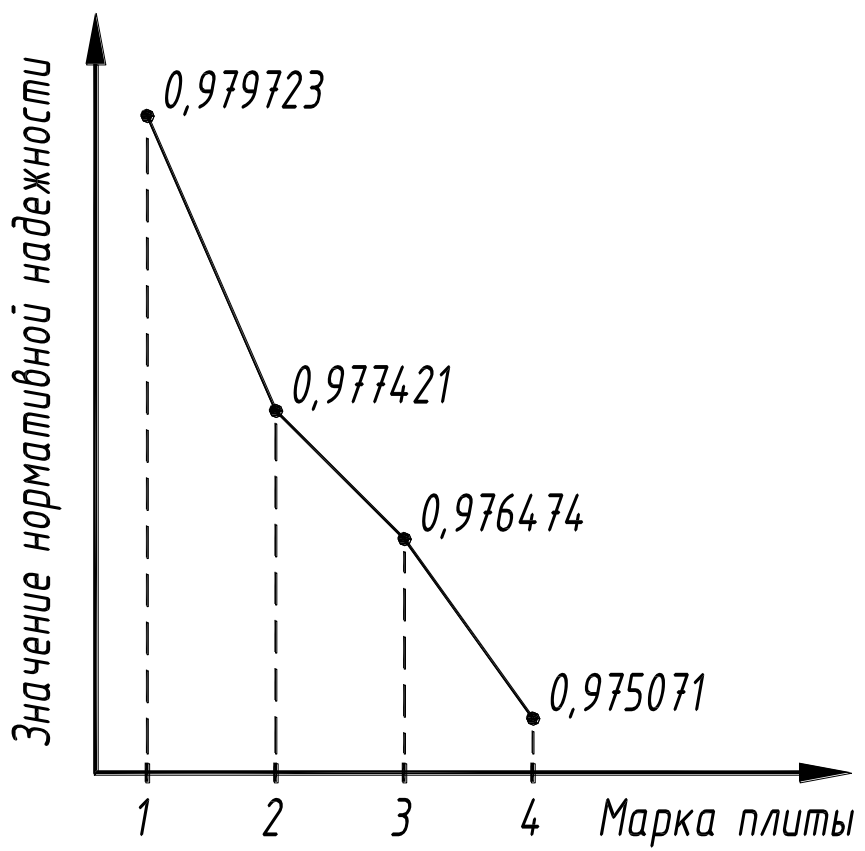

Puc. 4. Зависимость нормативной надежности от пролета плит (номинальная ширина 1,5 м, нагрузка -800 кг $\left./ \mathrm{M}^{2}\right)$ :

1 - плита ПК 54.15-8АтVт; 2 - плита ПК 57.15-8АтVт; 3 - плита ПК 60.158АтVт; 4 - плита ПК 63.15-8АтVт

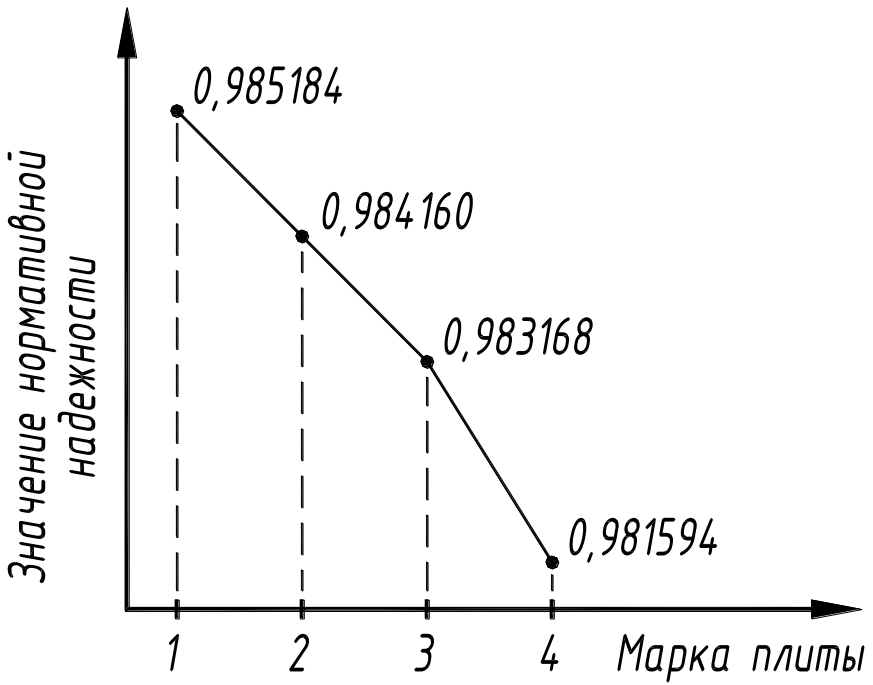

Puc. 5. Зависимость нормативной надежности от пролета плит (номинальная ширина 1 м, нагрузка -600 кг $\left./ \mathrm{m}^{2}\right)$ :

1 - плита ПК 51.10-6АтVт; 2 - плита ПК 54.10-6АтVт; 3 - плита ПК 57.106АтVт; 4 - плита ПК 60.10-6АтVт 


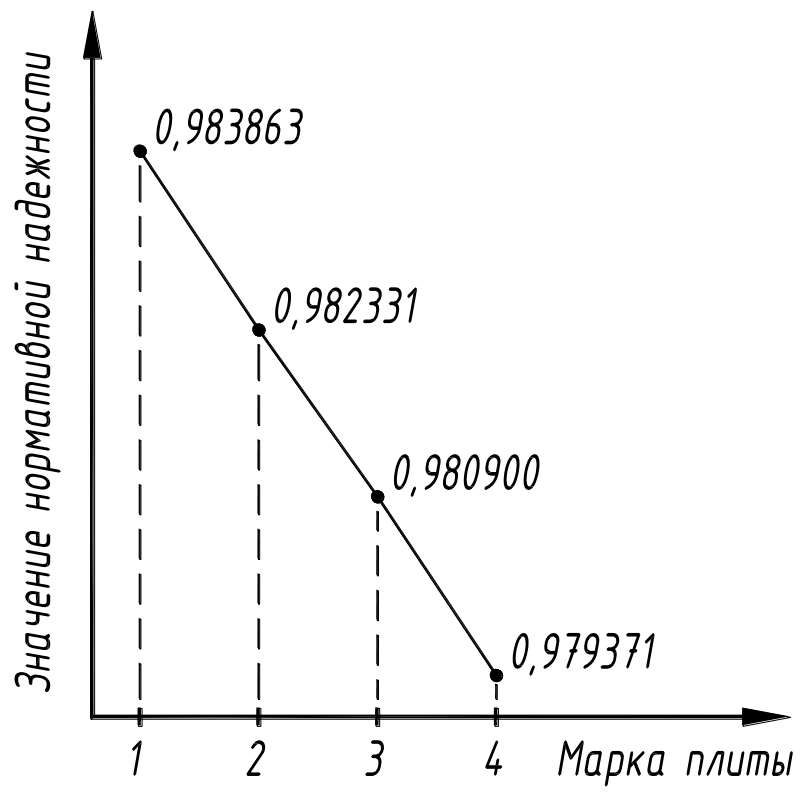

Puc. 6. Зависимость нормативной надежности от пролета плит (номинальная ширина 1,2 м, нагрузка $\left.-600 \mathrm{\kappa г} / \mathrm{M}^{2}\right)$ :

1 - плита ПК 54.12-6АтVт; 2 - плита ПК 57.12-6АтVт; 3 - плита ПК 60.126АтVт; 4 - плита ПК 63.12-6АтVт

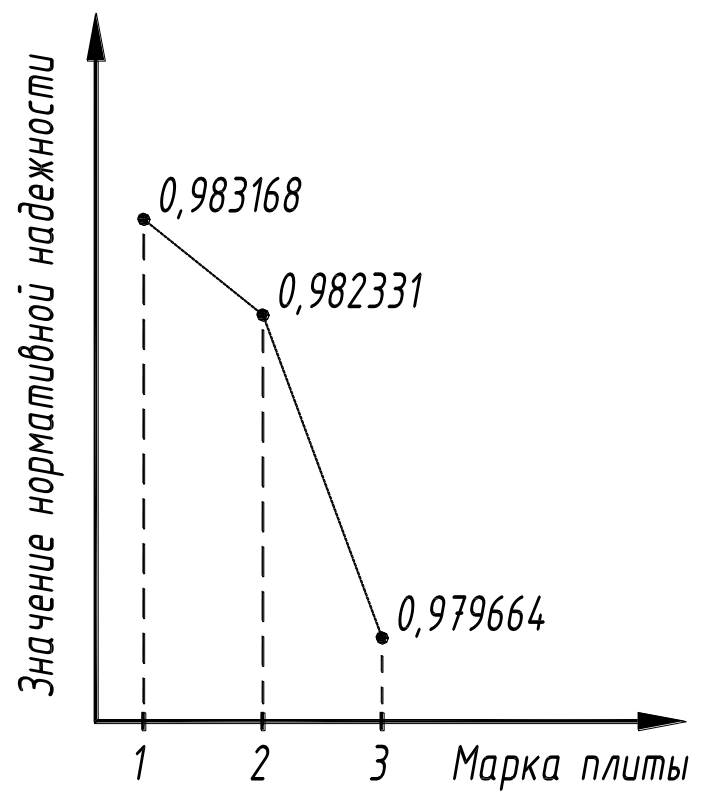

Puc. 7. Зависимость нормативной надежности от ширины плит (номинальная длина плит $-5,7$ м, нагрузка -600 кг $\left./ \mathrm{M}^{2}\right)$ :

1 - плита ПК 57.10-6АтVт; 2 - плита ПК 57.12-6АтVт; 3 - плита ПК 57.15-6АтVт 


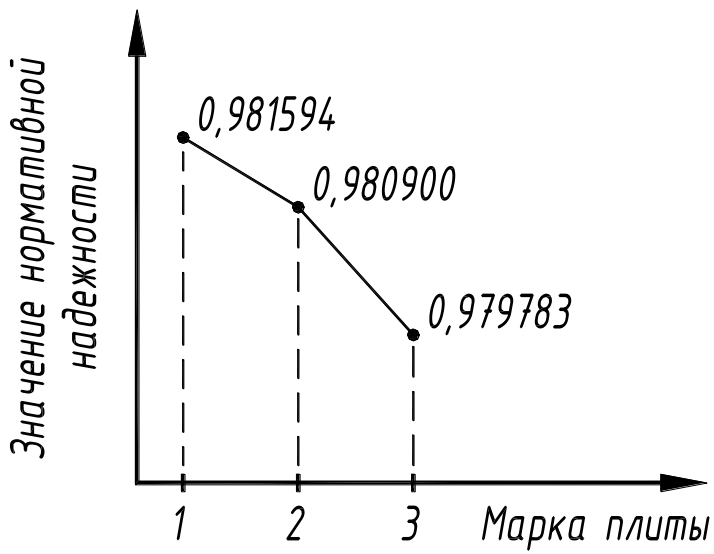

Puc. 8. Зависимость нормативной надежности от ширины плит (номинальная длина плит $-6,0$ м, нагрузка -600 кг $\left./ \mathrm{M}^{2}\right)$ :

1 - плита ПК 60.10-6АтVт; 2 - плита ПК 60.12-6АтVт; 3 - плита ПК 60.15-6АтVт

Таким образом, значение нормативной надежности по деформациям при учете только физиологических требований не является конкретной фиксированной величиной. Значение зависит от размеров конструкции (пролета, ширины) и величины действующей нагрузки.

Предлагаемая методика позволяет определить значение нормативной надежности только при учете физиологических требований к деформациям. Окончательное значение нормативной надежности должно быть определено с учетом всех остальных требований, предъявляемых к предельным деформациям.

\section{БИБЛИОГРАФИЧЕСКИЙ СПИСОК}

1. Шnете Г. Надежность несущих строительных конструкций. Москва : Стройиздат, 1994. $288 \mathrm{c}$.

2. Таль К.Э. Вопросы надежности железобетонных сооружений за рубежом // Бетон и железобетон. 1973. № 11. С. 42-43.

3. Громаикий B.A. Оценка надежности железобетонных изгибаемых элементов по деформациям // Строительная механика и расчет сооружений. 2007. № 2. С. 35-40.

4. Тамарзян А.Г. К оценке определения уровня риска ЧС по основным признакам его проявления на сооружение // Бетон и железобетон. 2001. № 5. С. 8-10.

5. Райзер В.Д. Анализ надежности конструкций при износе несущих элементов // Строительная механика и расчет сооружений. 2013. № 6. С. 16-20.

6. Цейтлин А.И., Неустроев Э.А., Кобахидзе М.О. О динамической жесткости (зыбкости) междуэтажных перекрытий // Строительная механика и расчет сооружений. 1988. № 4. C. $30-33$.

7. Дегтярева Н.В. Моделирование колебаний железобетонных большепролетных перекрытий, вызванных ходьбой человека // Строительная механика и расчет сооружений. 2013. № 3. C. 33-39.

8. Перельмутер А.В. Избранные проблемы надежности и безопасности строительных конструкций. Москва : Изд-во АСВ, 2007. 256 с.

9. Инструкиия по расчету несущих конструкиий промышленных зданий и сооружений на динамические нагрузки // ЦНИИСК им. Кучеренко. Москва : Стройиздат, 1970. 288 с

10. Ржанищын A.P. Теория расчета строительных конструкций на надежность. Москва : Стройиздат, 1978. 239 с. 
11. Краковский М. Б. Определение надежности конструкций методами статистического моделирования // Строительная механика и расчет сооружений. 1982. № 2. С. 10-13.

12. Лычев А.С. Надежность строительных конструкций. Москва : Изд-во АСВ, 2008. 184 с.

13. Закс Л. Статистическое оценивание / под ред. Ю.П. Аулера, В.Г. Горского. Москва : Статистика, 1976. $598 \mathrm{c}$.

\section{REFERENCES}

1. Shpete G. Nadezhnost' nesushchikh stroitel'nykh konstruktsii [Reliability of load-bearing structures]. Moscow: Stroiizdat, 1994. 288 p. (rus)

2. Tal' K.E. Voprosy nadezhnosti zhelezobetonnykh sooruzhenii za rubezhom [Reliability issues of reinforced-concrete structures abroad]. Beton i zhelezobeton. 1973 No. 11. Pp. 42-43. (rus)

3. Gromatskii V.A. Otsenka nadezhnosti zhelezobetonnykh izgibaemykh elementov po deformatsiyam [Reliability assessment of reinforced-concrete bending elements by deformations]. Stroitel'naya mekhanika i raschet sooruzhenii. 2007. No. 2. Pp. 35-40. (rus)

4. Tamarzyan A.G. K otsenke opredeleniya urovnya riska $\mathrm{ChS}$ po osnovnym priznakam ego proyavleniya na sooruzhenie [Assessment of the emergency risk level by its main signs in construction]. Beton i zhelezobeton. 2001. No. 5. Pp. 8-10. (rus)

5. Raizer V.D. Analiz nadezhnosti konstruktsii pri iznose nesushchikh elementov [Strength analysis during wear of load-bearing elements]. Stroitel'naya mekhanika i raschet sooruzhenii. 2013. No. 6. Pp. 16-20. (rus)

6. Tseitlin A.I., Neustroev E.A., Kobakhidze M.O. O dinamicheskoi zhestkosti (zybkosti) mezhduetazhnykh perekrytii [Dynamic stiffness (fluctuation) of floors]. Stroitel'naya mekhanika i raschet sooruzhenii. 1988. No. 4. Pp. 30-33. (rus)

7. Degtyareva N.V. Modelirovanie kolebanii zhelezobetonnykh bol'she-proletnykh perekrytii, vyzvannykh khod'boi cheloveka [Modeling of human-walking caused vibrations of reinforcedconcrete large-span ceilings]. Stroitel'naya mekhanika i raschet sooruzhenii. 2013. No. 3. Pp. 33-39. (rus)

8. Peremul'ter A.V. Izbrannye problemy nadezhnosti i bezopasnosti stroitel'nykh konstruktsii [Selected problems of structural reliability and safety]. Moscow: ASV, 2007. 256 p. (rus)

9. Instruktsiya po raschetu nesushchikh konstruktsii promyshlennykh zdanii i sooruzhenii na dinamicheskie nagruzki [Dynamic load calculation of supporting structures of industrial buildings]. Moscow: Stroiizdat, 1970. 288 p. (rus)

10. Rzhanitsyn A.R. Teoriya rascheta stroitel'nykh konstruktsii na nadezhnost' [Theory of structural reliability calculation]. Moscow: Stroiizdat, 1978. 239 p. (rus)

11. Krakovskii M.B. Opredelenie nadezhnosti konstruktsii metodami statisticheskogo modelirovaniya [Statistical modeling methods of structural reliability]. Stroitel'naya mekhanika i raschet sooruzhenii. 1982. No. 2. Pp. 10-13. (rus)

12. Lychev A.S. Nadezhnost' stroitel'nykh konstruktsii [Reliability of building structures]. Moscow: ASV, 2008. 184 p. (rus)

13. Zaks L. Statisticheskoe otsenivanie [Statistical assessment]. Yu.P. Auler and V.G. Gorskii, Eds. Moscow: Statistika, 1976. 598 p. (rus)

\section{Сведения об авторе}

Герасимов Евгений Петрович, канд. техн. наук, доцент, Новосибирский государственный университет архитектуры, дизайна и искусств, 630099, г. Новосибирск, Красный проспект, 38, Evgeniy_30_04_82@mail.ru

\section{Author Details}

Evgeniy P. Gerasimov, $\mathrm{PhD}, \mathrm{A} / \mathrm{Professor}$, Novosibirsk State University of Architecture, Design and Fine Arts, 38, Krasnyi Ave., 630099, Novosibirsk, Russia, Evgeniy_30_04_82@mail.ru 